\title{
Assessing the Technology Self-Efficacy of Maritime Instructors: An Explorative Study
}

\author{
Amit Sharma * and Salman Nazir
}

Citation: Sharma, A.; Nazir, S. Assessing the Technology Self-Efficacy of Maritime Instructors: An Explorative Study. Educ. Sci. 2021, 11, 342. https://doi.org/10.3390/ educsci11070342

Academic Editor: Eleanor Dommett

Received: 1 June 2021

Accepted: 8 July 2021

Published: 12 July 2021

Publisher's Note: MDPI stays neutral with regard to jurisdictional claims in published maps and institutional affiliations.

Copyright: (C) 2021 by the authors Licensee MDPI, Basel, Switzerland. This article is an open access article distributed under the terms and conditions of the Creative Commons Attribution (CC BY) license (https:// creativecommons.org/licenses/by/ $4.0 /)$.
Training and Assessment Research Group (TARG), Department of Maritime Operations, University of South-Eastern, 3199 Borre, Norway; sna@usn.no

* Correspondence: ams@usn.no

\begin{abstract}
Maritime Education and Training (MET) is an integral part of the global maritime industry, playing an essential role in ensuring that the sector is supplied continuously with a skilled workforce. The successful outcomes of the educational content delivery in MET institutes depend, to a certain extent, on the maritime instructor's ability to create conducive learning environments utilizing all of the resources available. The self-efficacy of maritime instructors in various facets, most notably their proficiency with the use of technology in classrooms, can lead to the introduction of transformative learning practices. Accurately measuring their self-reported technological proficiency could be the initial step in this direction. This study aimed to measure the self-reported technology proficiency of maritime instructors using an established and validated scale: Technology Proficiency Self-Assessment for the 21st century (TPSA-C21). The scale was administered, using an online survey, to a sample of MET instructors within Europe and the UK, with $n=62$ valid responses received. Using descriptive statistics and the evaluation of the measurement model, the study highlighted the perceived level of proficiency of the MET instructors along dimensions such as email, worldwide web use, emerging tools, teaching with technology, integrated applications, and teaching with emerging technologies. The survey also measured the perceived level of technology integration for maritime instructors according to the Concerned-Based Adoption Model-Level of Use (CBAM$\mathrm{LoU})$ classification. The results indicate a potential area of improvement for maritime instructors with regard to their self-reported proficiency, namely in the dimension of teaching with emerging technology. The implications for the MET domain, the respondent demographics and the future research directions are discussed.
\end{abstract}

Keywords: maritime education and training; maritime pedagogy; TPSA-C21; self-efficacy

\section{Introduction}

Maritime Education and Training has been referred to as one of the six pillars of the global maritime industry by the International Maritime Organization [1]. The maritime industry plays an indispensable role in the global economy, and enables trade and the movement of goods and services across various continents. The European region has historically been recognized as influential in the maritime industry due to the presence of key maritime clusters in the region, which have traditionally facilitated knowledge exchange, collaboration, research, and the development of maritime technology [2]. About 43,000 ships ply the European waters alone; they are instrumental in the transport of valuable goods and passengers, and in the value creation and sustainable solutions in the supply chain of the region [3]. The availability of technical capital in the region has also been simultaneously linked with the presence of human capital itself, with maritime professionals and seafarers providing the knowledge and experience for the operations. The availability of this relevant human capital is supported by the well-established Maritime Education and Training (MET) institutes in the region. There are numerous MET universities and vocational MET institutes in Europe (and the UK) [4], providing various courses and 
programs for competence development, the fulfilment of the regulatory requirements, and research and development in the maritime sector.

The operational environment related to the maritime domain has evolved steadily over the years. From isolated floating workspaces with labour-intensive working arenas, ships have transformed into valuable assets which are linked using Information and Communication Technologies (ICTs) to the larger supply chain involved in the movement of goods [5]. Many modern ship operations are managed or assisted via shore offices at present. A parallel trend has been replacement of many functions onboard with automation, with crew members primarily supervising the performance of the automation agents. Correspondingly, the crew size has shown a trend of reduction, along with a change in their skillsets and competence requirements. Many researchers have addressed these developments, with commentary on the need for ICT skills training for contemporary seafarers [6,7] along with the need to balance the academic aspects of MET with the predominant vocational aspects [8].

The technological innovations of the 21st century are leading us towards changes in the dynamics of education and its delivery globally. The advancements in Information and Communication Technologies (ICTs) have resulted in the availability of educational solutions that enable the ubiquitous delivery of content and novel opportunities for communication and collaboration when engaging with that content. The maritime domain has also adopted modern ICTs and developments in the learning sciences through the use of distance learning, simulator-based learning, e-learning and other initiatives $[9,10]$. Some other emerging trends that hold substantial potential for Maritime Education and Training are Artificial Intelligence and Virtual/Augmented Reality [7,11]. However, the utilization of any technology or its integration into classrooms, to a certain extent, depends upon the teachers and instructors, who are typically responsible for achieving the learning objectives set out in the educational programs [12]. Even though we have seen a considerable increase in the use of distributed learning solutions in recent years, traditional hierarchical learning solutions-in which the training and education are facilitated in an established institution and mediated by instructors - are still relevant for a majority of maritime operations.

Technology integration in the classroom can be generally defined as the use of technological resources such as personal computers, laptops, smart phones, tablets, and other devices with or without internet support for carrying out activities related to the learning and assessment. Davies and West [13] (p. 843) gave a more formal definition as "the effective implementation of educational technology to accomplish learning outcomes". Educational technology itself can be any tool or device, whether electronic or mechanical, that can be used for achieving the intended learning goals. In the learning sciences, various models of technology integration for classrooms have been proposed over the past several years [14]. The models for technology integration can further be divided into the models that focus on the removal of barriers that hinder the use of ICTs in the classrooms [15] and the models that focus on the personal skill set of the instructors and their proficiency with the ICTs [16].

The arguments in support of technology integration are numerous, the most prominent being the need for the cultivation of 21st century skills, such as communication, collaboration, critical thinking and creativity, etc. $[17,18]$. The possession of such a skillset is thought to be a requirement for a generic worker in any socio-technical system, including the maritime domain [19], in which human and automation agents work in tandem with close and continuous collaboration. As Artificial Intelligence and Digitalization make further inroads in the maritime domain, it will require a reimagination of the operational processes, with the automation agents taking over most of the redundant and repetitive tasks, whereas the human operators are expected to be able to augment their creative and reasoning abilities to enhance the system performance and ensure safe outcomes [11]. Such a change, although gradual, can be expected to take place in the coming years. It would require an appropriate response from the researchers and practitioners associated with the MET community to ensure that the seafarers are ready to face technological challenges 
through the possession of appropriate skills and competencies. In addition, the current pandemic of COVID-19 has also put constraints on the infrastructure of MET institutes. The pandemic has necessitated the adoption of measures to ensure that remote and e-learning measures are in place to continue the training and assessment of maritime trainees. Here, the maritime instructors, who are responsible for the education of future seafarers, play a crucial role. The maritime instructors who are responsible for instilling the required competencies to the maritime trainees use various instructional tools and resources to ensure the satisfactory transfer of knowledge in the classrooms and simulators [20,21]. The ongoing changes in the learning environment related to the use of a variety of digital affordances and existing infrastructure put the focus on the resources made available to the maritime instructors and their self-perceived efficacy in their use.

In light of above, the primary research objective for this study is to assess the technology self-efficacy of the maritime instructors. Utilizing a validated scale to measure the self-reported technological proficiency of the maritime instructors could aid in mapping and identifying areas of possible improvement. In this paper, we utilize the Technology Proficiency Self-Assessment for the 21st Century (TPSA-C21) questionnaire for the measurement of the self-reported technological proficiency of maritime instructors from a selection of MET institutes in Europe and the UK. In the subsequent sections, first, a brief review of the associated terms and literature is carried out. The context of the present study is also elaborated upon. Furthermore, the methods for conducting the data collection and analysis are described. This is followed by a description of the obtained research results from the study and discussions highlighting the contribution, limitations and potential areas of future research.

\section{Context and Literature Review}

The maritime industry depends on certain factors to ensure safe outcomes in day-today operations, with one of them being a qualified and skilled workforce. The elemental function of the maritime industry is to transport goods and services across the globe. It employs high value assets, i.e., ships, towards this end, which are manned by seafarers. The International Maritime Organization (IMO), through the Standards of Training, Certification and Watchkeeping (STCW) regulations, aim to ensure standardization in seafarer's qualifications for all of the signatory member states. According to the European Maritime Safety Agency, about 210,000 masters and officers are working on ships that possess a valid Certificate of Competency ( $\mathrm{CoC})$ issued by an EU member state [22]. In order to possess a valid CoC and other mandatory certificates following the provisions of the STCW, the seafarers have to undergo various stipulated courses in an approved Maritime Education and Training (MET) institute. MET institutes, therefore, make an important contribution towards ensuring the supply of a skilled workforce for the maritime industry. As there has been a steady demand for skilled and qualified seafarers for the maritime industry over the decades [23], and given the fact that many of these certifications often also require periodic renewals, the MET institutes have a dynamic and evolving role to perform. The STCW regulations have been revised in the past to keep up with the changing workplace environment and, as a consequence, competence requirements within the maritime industry [11]. This has been the case with MET institutes and the modes of educational content delivery [24]. The MET institutes not only need to possess adequate infrastructure to utilize various modes of educational content delivery; there is also a need for the maritime instructors to continuously update their pedagogical profile and explore the use of digital technologies. STCW regulation I/ 6 stipulates that the person responsible for conducting courses that lead up to the issuance of a certificate for a seafarer should also be adequately qualified. As a response, the IMO came up with Model Course 6.09 "Train the Trainer" and 6.10 "Train the simulator trainer and assessor", which, amongst other things, focus on the role of instructor, the learning process, the design of the training program, and the use of teaching aids. The development of a pedagogical profile and continuous professional development of maritime instructors are therefore deemed important for the maritime 
industry. The instructors should feel sufficiently confident in their own ability to utilize the technological tools available to them to impart lessons pertaining to the courses.

Technology integration has received increasing attention in the studies related to educational sciences in recent years. This can be partly ascribed to the increasing availability of digital tools in educational content design and delivery [25]. Whereas the use of any technological tool does not guarantee the better transfer of training, it does transform the nature of the educational delivery [26]. Some of the ICT tools can increase the instructor's outreach and improve their efficiency if utilized properly. Instructors engaged in vocational education and training are increasingly adopting novel modes of educational content delivery to improve the learning outcomes for the educational programs [27,28]. Various studies have pointed to the fact that the use of technological tools by the instructors in the classrooms depends on their self-efficacy towards them [29,30]. Self-efficacy, in simple terms, can be defined as the belief of an individual that the task he or she is performing will lead to the desired outcomes. Self-efficacy as a concept has underpinnings in Social Cognitive Theory [31]. Bandura [32] stated that self-efficacy could be a good predictor of a behavior. It is also termed as one of the factors that influences the effectiveness of the teaching [33].

Measuring and improving self-efficacy in the use of technological tools for the instructors can therefore help in their capacity development. In this regard, Christensen and Knezeck [34] argue that the ability to integrate 21st century technology for learning and proficiency in the use of these technologies has a vital role in modern educational institutions. They proposed a validated instrument known as the Technology Proficiency Self-Assessment for the 21st Century (TPSA-C21) for the measurement of self-reported self-efficacy scores for the instructors, with reference to the prominent technological tools adopted in the contemporary classrooms. The theoretical underpinnings of the scale were discussed by Christensen and Knezeck (p. 312, [35]); they stated that it is grounded in the concept of "Self-efficacy", which they defined as "confidence in one's competence". The scale was adapted from the earlier version of the instrument, known as the Technology Proficiency Self-Assessment (TPSA), which was developed by Ropp [36]. It has previously been used by [37] to measure confidence in integrating technology into classrooms in the USA, and by [38] as a measure which was further correlated with the age, gender and subject area of the respondents. The original TPSA scale measured technology proficiency in four dimensions, i.e., using electronic mail (Email), using the world wide web (WWW), using technology applications, and proficiency in teaching with technology [39]. After reviewing the performance of the scale and taking into account the recent developments, two more dimensions of technological proficiency, namely emerging tools and teaching with emerging technologies, were included in the scale by Christensen and Knezeck [34]. The six sub scales, along with their definitions, are described below:

- Email: the ability to send a document as an attachment to an email message.

- WWW: the ability to find the primary resources of information on the internet that can be used in teaching.

- Emerging tools: the ability to save and retrieve files from a cloud-based environment.

- Teaching with technology: the ability to use technology to collaborate with teachers or students who are distant from the classroom.

- Integrated applications: the ability to use a spreadsheet to create a bar graph of the proportions of different colours.

- Teaching with emerging technologies: the ability to teach in a one-to-one environment in which the students have their own devices.

These six sub-scales, taken together, aim to provide a measure of the technology proficiency of the instructors. The instrument can also be used to compare groups of instructors, or to carry out a longitudinal study on the same group of instructors to measure any change due to training interventions. Accurately measuring the technology self-efficacy of the MET instructors can be the first step in identifying their training requirements and the need for policy interventions, if any. To the best of our knowledge, the quantitative 
assessment of self-reported technology proficiency or technology self-efficacy for maritime instructors in the European context has not been attempted in the existing research literature related to MET. In the next section, we elaborate upon the steps followed to achieve this aim.

\section{Methods}

In order to achieve the research objective, the TPSA-C21 questionnaire was digitalized in the platform Nettskjema ${ }^{\circledR}$, a Norwegian secure service solution for data collection which supports the drafting process of online survey links. There are a total of 34 questions in the TPSA-C21 questionnaire, which together provide the scores related to the 6 sub-scales. Their grouping is as follows: Email (Q.1-5), WWW (Q.6-10), Integrated Applications (Q.1115), Teaching with technology (Q.16-20), Teaching with emerging technologies (Q.21-28) and Emerging tools (Q.29-34). The online link of the questionnaire was distributed to the professional contacts, who were MET instructors within a European MET (additionally in the UK) institute using an email platform. The scope of the study was limited to Europe and the UK in order to ensure the sufficient generalizability of the research outcomes. The respondents were asked to rate each item from "Strongly Disagree" to "Strongly Agree" and anything in between Likert scale numbering 1 to 5. A few demographics questions, such as Gender, Age, Years of experience, and Country of origin were also inserted at the beginning in order to facilitate the understanding of the obtained data. Furthermore, towards the end of the questionnaire, the respondents were also asked to rate their level of technology proficiency using the Level of Use scale [40]. This is a self-assessment instrument based on the Concern Based Adoption Model (CBAM), and it lists 8 levels of educational innovation: (1) Non-use, (2) Orientation, (3) Preparation, (4) Mechanical use, (5) Routine, (6) Refinement, (7) Integration, and (8) Renewal [41]. All of the ethical guidelines of the affiliated institution regarding anonymity and data collection were followed. The ethical permission to collect and process the data was obtained from the Norwegian Centre for Research Data (NSD) via a notification form, reference number 471618, in March 2020.

The method of data collection was a non-random, purposive sampling approach through the professional networks of MET universities. The data collection stage lasted from May 2020 to November 2020. At the end of this period, a total number of 76 responses were obtained. The data was then checked for anomalies, and 14 responses were removed due to either being incomplete or straight-lining the responses. Finally, a total number of $n=$ 62 valid responses were extracted which were deemed fit for further analysis. The data was then analyzed for descriptive statistics and measurement model assessment using Microsoft Excel $^{\circledR}$, and the statistical software packages SPSS ${ }^{\circledR}$ and SmartPLS3 ${ }^{\circledR}$. The calculation of the descriptive statistics and the non-parametric statistical test, for the examination of the differences in means by groups such as educational qualifications and years of experience using the Kruskal-Wallis test was conducted through SPSS ${ }^{\circledR}$. For the measurement model assessment through Confirmatory Composite Analysis (CCA), SmartPLS3 ${ }^{\circledR}$ was utilized, along with the guidelines given by Hair et al. [42,43]. Accordingly, the factor loadings for items under each dimension, Composite Reliability, Cronbach's Alpha, Rho Alpha, Average Variance Extracted and Heterotrait-Monotrait ratios were obtained. For the nonparametric Kruskal-Wallis test, Chi-square and P significance values were obtained for the comparison. The average age of the respondent was 43.0 years ( $\mathrm{SD}=5.46$ years). The rest of the demographic data is summarized in Table 1. Most of the respondents stated their country of origin as Norway (29\%), followed by Sweden (17.7\%), Denmark $(12.9 \%)$, the UK $(9.7 \%)$, Germany $(6.4 \%)$, Belgium (4.8\%), and the Netherlands (1.6\%). The rest $(17.9 \%)$ did not specify their country of origin. The obtained scores and values for various statistics for the TPSA-C21 sub-scales and each item under them are described in detail and discussed in the next section. 
Table 1. Demographic characteristics of the respondents.

\begin{tabular}{cccc}
\hline Demographic & & Frequency & Percent \\
\hline \multirow{2}{*}{ Gender } & Male & 52 & 83.9 \\
& Female & 10 & 16.1 \\
Educational & Bachelors & 10 & 16.1 \\
Qualifications & Masters & 36 & 58.0 \\
& Doctorate & 13 & 21.0 \\
& Other & 3 & 4.9 \\
Years of experience & $0-5$ years & 17 & 27.4 \\
& $6-10$ & 14 & 22.6 \\
& $11-15$ & 10 & 16.1 \\
& +15 years & 21 & 33.9 \\
\hline
\end{tabular}

\section{Results}

The TPSA-C21 scores for each of the subscales are elaborated below.

\subsection{Email}

The Email subscale consisted of five items. Their individual scores, factor loading, reliability value and Kruskal-Wallis test results are given below (Table 2).

Table 2. Self-reported proficiency of maritime instructors along the dimension 'Email'.

\begin{tabular}{|c|c|c|c|c|c|}
\hline Q.No. & Mean & SD & $\begin{array}{l}\text { Factor } \\
\text { Loading }\end{array}$ & $\begin{array}{l}\text { Qualifications } \\
\text { Chi.sq/Sig. }\end{array}$ & $\begin{array}{l}\text { Experience } \\
\text { Chi.sq/Sig. }\end{array}$ \\
\hline Q.1-Send an email to friend & 4.74 & 0.57 & 0.767 & $7.055 / 0.070$ & $1.667 / 0.664$ \\
\hline Q.2-Subscribe to a discussion list & 4.68 & 0.59 & 0.896 & $7.058 / 0.070$ & $1.923 / 0.589$ \\
\hline $\begin{array}{l}\text { Q.3-Create a distribution list to } \\
\text { send email to several people at once }\end{array}$ & 4.60 & 0.69 & 0.759 & $12.990 / 0.005 *$ & $2.380 / 0.497$ \\
\hline $\begin{array}{l}\text { Q.4-Send a document as an } \\
\text { attachment to an email }\end{array}$ & 4.81 & 0.47 & 0.860 & $11.982 / 0.007^{*}$ & $4.286 / 0.232$ \\
\hline $\begin{array}{l}\text { Q.5-Keep copies of outgoing } \\
\text { message that I send to others }\end{array}$ & 4.73 & 0.55 & 0.841 & $16.226 / 0.001 *$ & $4.260 / 0.235$ \\
\hline
\end{tabular}

\subsection{World Wide Web}

The World Wide Web subscale consisted of five items. Their individual scores, factor loading, reliability values and Kruskal-Wallis test results are given below (Table 3).

Table 3. Self-reported proficiency of maritime instructors along the dimension 'World Wide Web'.

\begin{tabular}{|c|c|c|c|c|c|}
\hline Q.No. & Mean & SD & $\begin{array}{l}\text { Factor } \\
\text { Loading }\end{array}$ & $\begin{array}{l}\text { Qualifications } \\
\text { Chi.sq/Sig. }\end{array}$ & $\begin{array}{l}\text { Experience } \\
\text { Chi.sq/Sig. }\end{array}$ \\
\hline $\begin{array}{l}\text { Q.6-Use internet search engine to } \\
\text { find Web pages related to my } \\
\text { subject matter interests }\end{array}$ & 4.85 & 0.40 & 0.713 & $10.146 / 0.017$ & $1.614 / 0.656$ \\
\hline $\begin{array}{l}\text { Q.7-Search for and find } \\
\text { Smithsonian institute website }\end{array}$ & 4.60 & 0.84 & 0.852 & $9.017 / 0.029$ & $4.895 / 0.180$ \\
\hline $\begin{array}{c}\text { Q.8-Create my own webpage } \\
\text { Q.9-Keep track of websites I have }\end{array}$ & 3.37 & 1.26 & 0.464 & $0.990 / 0.804$ & $1.461 / 0.691$ \\
\hline $\begin{array}{l}\text { visited so that I can return to them } \\
\text { later }\end{array}$ & 4.56 & 0.82 & 0.865 & $10.534 / 0.015$ & $2.505 / 0.474$ \\
\hline $\begin{array}{l}\text { Q.10-Find primary sources of } \\
\text { information on the internet that I } \\
\text { can use in my teaching }\end{array}$ & 4.65 & 0.66 & 0.854 & $14.630 / 0.002 *$ & $3.402 / 0.334$ \\
\hline
\end{tabular}

\subsection{Integrated Applications}

The Integrated applications subscale consisted of five items. Their individual scores, factor loading, reliability value and Kruskal-Wallis test results are given below (Table 4). 
Table 4. Self-reported proficiency of maritime instructors along the dimension 'Integrated Applications'.

\begin{tabular}{|c|c|c|c|c|c|}
\hline Q.No. & Mean & SD & $\begin{array}{l}\text { Factor } \\
\text { Loading }\end{array}$ & $\begin{array}{l}\text { Qualifications } \\
\text { Chi.sq/Sig. }\end{array}$ & $\begin{array}{l}\text { Experience } \\
\text { Chi.sq/Sig. }\end{array}$ \\
\hline $\begin{array}{l}\text { Q.11-Use spreadsheets to create a } \\
\text { bar graph of the proportions of } \\
\text { different colours }\end{array}$ & 4.26 & 1.02 & 0.879 & $8.805 / 0.032$ & $2.817 / 0.421$ \\
\hline $\begin{array}{l}\text { Q.12-Create a newsletter with } \\
\text { graphics }\end{array}$ & 4.00 & 1.19 & 0.811 & $5.723 / 0.126$ & $1.589 / 0.662$ \\
\hline $\begin{array}{l}\text { Q.13-Save documents in formats } \\
\text { so that others can read them if they } \\
\text { have different word processing } \\
\text { programs }\end{array}$ & 4.60 & 0.80 & 0.884 & $14.141 / 0.003 *$ & $1.537 / 0.674$ \\
\hline $\begin{array}{l}\text { Q.14-Use the computer to create a } \\
\text { slideshow presentation }\end{array}$ & 4.81 & 0.47 & 0.802 & $20.729 / 0.000 *$ & $3.116 / 0.374$ \\
\hline $\begin{array}{l}\text { Q.15-Create a database of } \\
\text { information about important } \\
\text { authors in a subject matter field }\end{array}$ & 4.08 & 1.03 & 0.726 & $8.361 / 0.039$ & $1.112 / 0.774$ \\
\hline
\end{tabular}

\subsection{Teaching with Technology}

The Teaching with technology subscale consisted of five items. Their individual scores, factor loading, reliability value and Kruskal-Wallis test results are given below (Table 5).

Table 5. Self-reported proficiency of maritime instructors along the dimension 'Teaching with technology'.

\begin{tabular}{|c|c|c|c|c|c|}
\hline Q.No. & Mean & SD & $\begin{array}{l}\text { Factor } \\
\text { Loading }\end{array}$ & $\begin{array}{l}\text { Qualifications } \\
\text { Chi.sq/Sig. }\end{array}$ & $\begin{array}{l}\text { Experience } \\
\text { Chi.sq/Sig. }\end{array}$ \\
\hline $\begin{array}{l}\text { Q.16-Write an essay describing } \\
\text { how I would use technology in my } \\
\text { classroom }\end{array}$ & 4.45 & 0.84 & 0.770 & $9.109 / 0.028$ & $4.277 / 0.233$ \\
\hline $\begin{array}{l}\text { Q.17-Create a lesson or unit that } \\
\text { incorporates subject matter } \\
\text { software as an integral part }\end{array}$ & 4.06 & 0.97 & 0.855 & $9.122 / 0.028$ & $3.519 / 0.318$ \\
\hline $\begin{array}{c}\text { Q.18-Use technology to } \\
\text { collaborate with teachers or } \\
\text { students, who are distant from my } \\
\text { classroom }\end{array}$ & 4.53 & 0.72 & 0.850 & $11.822 / 0.008 *$ & $3.415 / 0.332$ \\
\hline $\begin{array}{c}\text { Q.19-Describe } 5 \text { software } \\
\text { programs or apps that I would use } \\
\text { in my teaching }\end{array}$ & 4.03 & 1.09 & 0.732 & $13.021 / 0.005^{*}$ & $3.225 / 0.358$ \\
\hline $\begin{array}{l}\text { Q.20-Write a plan with a budget to } \\
\text { buy technology for my classroom }\end{array}$ & 4.10 & 1.02 & 0.777 & $14.592 / 0.002 *$ & $1.208 / 0.751$ \\
\hline
\end{tabular}

Note: SD = standard deviation; Chi.sq = chi square; Sig = significance; ${ }^{*}=$ significant at the $p<0.01$ level.

\subsection{Teaching with Emerging Technology}

The Teaching with emerging technologies subscales consisted of eight items. Their individual scores, factor loading, reliability value and Kruskal-Wallis test results are given below (Table 6).

\subsection{Emerging Tools}

The Emerging tools subscale consisted of six items. Their individual scores, factor loading, reliability value and Kruskal-Wallis test results are given below (Table 7). 
Table 6. Self-reported proficiency along the dimension 'Teaching with emerging technology'.

\begin{tabular}{|c|c|c|c|c|c|}
\hline Q.No. & Mean & SD & $\begin{array}{l}\text { Factor } \\
\text { Loading }\end{array}$ & $\begin{array}{l}\text { Qualifications } \\
\text { Chi.sq/Sig. }\end{array}$ & $\begin{array}{l}\text { Experience } \\
\text { Chi.sq/Sig. }\end{array}$ \\
\hline $\begin{array}{c}\text { Q.21-Integrate mobile } \\
\text { technologies into my curriculum }\end{array}$ & 4.11 & 0.96 & 0.823 & $7.065 / 0.070$ & $1.146 / 0.766$ \\
\hline $\begin{array}{l}\text { Q.22-Use social media tools for } \\
\text { instruction in the classroom }\end{array}$ & 3.47 & 1.46 & 0.616 & $7.046 / 0.070$ & $0.672 / 0.880$ \\
\hline $\begin{array}{l}\text { Q.23-Create a wiki or blog to have } \\
\text { my students collaborate }\end{array}$ & 3.47 & 1.22 & 0.706 & $5.104 / 0.164$ & $2.649 / 0.449$ \\
\hline $\begin{array}{l}\text { Q.24-Use online tools to teach my } \\
\text { students from a distance }\end{array}$ & 4.48 & 0.80 & 0.814 & $3.925 / 0.270$ & $1.490 / 0.685$ \\
\hline $\begin{array}{l}\text { Q.25-Teach in one to one } \\
\text { environment in which students } \\
\text { have their own device }\end{array}$ & 4.44 & 0.74 & 0.714 & $4.314 / 0.229$ & $4.170 / 0.244$ \\
\hline $\begin{array}{l}\text { Q.26-Find a way to use } \\
\text { smartphone in my classroom for } \\
\text { student responses }\end{array}$ & 4.15 & 1.02 & 0.883 & $6.732 / 0.081$ & $2.596 / 0.458$ \\
\hline $\begin{array}{l}\text { Q.27-Use mobile devices to } \\
\text { connect with others for my } \\
\text { professional development }\end{array}$ & 4.13 & 1.00 & 0.846 & $3.162 / 0.367$ & $3.981 / 0.263$ \\
\hline $\begin{array}{l}\text { Q.28-Use mobile devices to have } \\
\text { my students access to learning } \\
\text { activities }\end{array}$ & 4.18 & 0.97 & 0.885 & $4.831 / 0.185$ & $3.859 / 0.277$ \\
\hline
\end{tabular}

Table 7. Self-reported proficiency of maritime instructors along the dimension 'Emerging tools'.

\begin{tabular}{|c|c|c|c|c|c|}
\hline Q.No. & Mean & SD & $\begin{array}{l}\text { Factor } \\
\text { Loading }\end{array}$ & $\begin{array}{l}\text { Qualifications } \\
\text { Chi.sq/Sig. }\end{array}$ & $\begin{array}{l}\text { Experience } \\
\text { Chi.sq/Sig. }\end{array}$ \\
\hline $\begin{array}{l}\text { Q.29-Download and listen to } \\
\text { podcasts/audiobooks }\end{array}$ & 4.42 & 0.80 & 0.885 & $10.011 / 0.018$ & $2.386 / 0.496$ \\
\hline Q.30-Download and read e-books & 4.48 & 0.78 & 0.915 & $13.894 / 0.003 *$ & $2.626 / 0.453$ \\
\hline $\begin{array}{l}\text { Q.31-Download and view } \\
\text { streaming movies/videoclips }\end{array}$ & 4.56 & 0.74 & 0.908 & $6.441 / 0.092$ & $4.754 / 0.191$ \\
\hline $\begin{array}{c}\text { Q.32-Send and receive text } \\
\text { messages }\end{array}$ & 4.74 & 0.48 & 0.573 & $9.311 / 0.025$ & $4.702 / 0.195$ \\
\hline $\begin{array}{l}\text { Q.33-Transfer photos or other data } \\
\text { via a smartphone }\end{array}$ & 4.76 & 0.62 & 0.892 & $7.505 / 0.057$ & $2.031 / 0.566$ \\
\hline $\begin{array}{l}\text { Q.34-Save and retrieve files in a } \\
\text { cloud based environment }\end{array}$ & 4.58 & 0.74 & 0.876 & $7.308 / 0.063$ & $1.230 / 0.746$ \\
\hline
\end{tabular}

Note: SD = standard deviation; Chi.sq = chi square; Sig = significance; ${ }^{*}=$ significant at the $p<0.01$ level.

Table 8, below, represents the Cronbach's Alpha (CA), Composite Reliability (CR), Rho Alpha and Average Variance Extracted (AVE) values. The first three measures denote the dimensions' construct validities, while AVE denotes the convergent validity.

Table 8. Cronbach's Alpha (CA), Composite Reliability (CR), Average Variance Extracted and Rho_Alpha.

\begin{tabular}{ccccc}
\hline Dimension & CA & CR & Rho-Alpha & AVE \\
\hline Email & 0.883 & 0.915 & 0.895 & 0.683 \\
WWW & 0.814 & 0.871 & 0.865 & 0.585 \\
Integrated Applications (IA) & 0.879 & 0.912 & 0.890 & 0.677 \\
Teaching with technology (TWT) & 0.857 & 0.897 & 0.863 & 0.637 \\
Teaching with emerging & 0.912 & 0.930 & 0.927 & 0.626 \\
technology (TWET) & 0.920 & 0.939 & 0.949 & 0.723 \\
Emerging tools (ET) & & &
\end{tabular}

Table 9, below, describes the Heterotrait-Monotrait ratio values as a measure of the dimension's discriminant validity. 
Table 9. Heterotrait-Monotrait Ratio (HTMT) values of the dimensions.

\begin{tabular}{ccccccc}
\hline Dimension & Email & WWW & IA & TWT & TWET & ET \\
\hline Email & - & - & - & - & - & - \\
WWW & 0.913 & - & - & - & - & - \\
Integrated Applications & 0.745 & 0.928 & - & - & - & - \\
Teaching with technology & 0.738 & 0.871 & 0.986 & - & - & - \\
Teaching with emr. & 0.463 & 0.542 & 0.765 & 0.840 & - & - \\
technology & 0.730 & 0.595 & 0.820 & 0.802 & 0.784 & - \\
Emerging tools & & & &
\end{tabular}

Table 10, below, describes the frequency and percentage distribution of the maritime instructors, marking them as belonging to one of the levels (0-6) of the CBAM-LoU classification in their ability to integrate technology for their own use.

Table 10. Concern-Based Adoption Model-Level of Use (CBAM-LoU) frequency distribution.

\begin{tabular}{cccc}
\hline Level of Use & Frequency & Percent & C. Percent \\
\hline Level 0-Non use & - & - & - \\
Level 1-Orientation & - & - & - \\
Level 2-Preparation & 2 & 3.2 & 3.2 \\
Level 3-Mechanical use & 15 & 24.2 & 27.4 \\
Level 4A-Routine & 26 & 41.9 & 69.4 \\
Level 4B-Refinement & 11 & 17.7 & 87.1 \\
Level 5-Integration & 8 & 12.9 & 100 \\
Level 6-Renewal & - & - & 100 \\
\hline
\end{tabular}

\section{Discussion}

The previous section highlighted and illustrated the results obtained, i.e., the score of the maritime instructors on the 34 questionnaire items and the six sub-scales aiming to measure their technology self-efficacy. All of the respondents scored more than 4.0 on average on the Likert scale for the TPSA-C21 questionnaire, except for Q.8, 22 and 23 . The scores obtained on these three questions were 3.37, 3.47 and 3.47, respectively. These scores were markedly low for any of the questionnaire item scores (refer to Tables 2-7). Although the instructors scored 4.0 or above in the rest of the questionnaire, which offers some evidence that they feel sufficiently proficient in the use of most of the technological tools in their teaching, the relatively lower scores on these questions indicate that instructors do not employ tools that can facilitate collaborative content creation and dissemination, and hint at the reluctance to capitalize on the affordances provided by Web 2.0.

In addition to the above, a non-parametric Kruskal-Wallis test was employed to detect the between-group differences in each of the items for two demographic categories, namely educational qualifications and years of experience. No a-priori threshold was declared for this test; however, it is necessary to compare the noticeable differences in the form of overlap or lack thereof in the mean distributions, as indicated by the obtained chi-square $/ p$-value statistics. The group distribution for the educational qualifications appears to be skewed, and therefore makes it more likely for the respondents to have differences in each item. However, the items, such as Q.3, 4, 5, 10, 13, 14, 18, 19, 20 and 30, showed relatively high chi-square values $(p<0.01)$, indicating that it is more likely that a difference in formal educational qualifications could mean difference in the usage of certain tools or measures, and correspondingly in the self-efficacy in those measures. This could also be the result of differences in the educational curriculum and delivery methods of different maritime universities. For example, the organizational structure, the instructors' formal qualification or their roles within the organization could be different if a maritime institution frequently offers diverse programs in higher levels (e.g., Masters and PhD level) as opposed to regular vocational or bachelor-level courses. For the tests conducted between groups with different years of experience in teaching, relatively lower chi-square values 
were obtained in comparison to the educational qualifications group. However, in the obtained sample, a relatively smaller difference in the group distribution percentage was also observed for groups with different years of experience, partly explaining such an outcome for the statistical test.

For the measurement model assessment, the guidelines mentioned by Hair et al. [42] were followed and a confirmatory composite analysis was performed. Firstly, the factor loading of each item was checked. The recommended value is greater than 0.708 , which was achieved by all of the items except Q.8, 22, 23 and 32. As we can observe from the descriptive statistics, the first three items also received relatively low scores in comparison to the rest of questionnaires, indicating low weightages within the associated constructs. Although Q.32 - Sending and receiving text messages—being a generic item, received a comparable score in its mean value, it still has less weightage for the construct's emerging tools. Furthermore, the measures of construct reliability, namely Cronbach's Alpha, Composite Reliability and Rho Alpha, had satisfactory values within the desired interval range from 0.70 to 0.95 . The measure of convergent validity, namely the Average Variance Extracted (AVE), was also above the required threshold of 0.50 , demonstrating the adequate convergent validity of the constructs. Lastly, the divergent validity was checked using Heterotrait-Monotrait ratios (HTMT). The recommended value, as per [42], is about 0.90. This was exceeded by a noticeable margin when comparing the "Teaching with technology" and "Integrated Applications" constructs in Table 9, indicating that the present measurement exercise and collected data could not satisfactorily distinguish between these two dimensions. Although the limited sample size would warrant caution regarding generalization or inference from this result, it is worth noting for future studies and the usage of the scale.

With respect to the distribution of the respondents according to their classification in the CBAM-LoU self-assessment scales, it is evident from Table 10 that the majority of the responses tended to be clustered around the middle of the spectrum. Most of the instructors (41.9\%) identified themselves to be at Level 4A, Routine, i.e., towards being able to comfortably use information technology in their teaching but not having managed to make more efforts to improve their teaching and its impact with use. This was followed by Level 3, Mechanical use (24.2\%) of the information technology. None of the respondents marked themselves in the extreme ends of the spectrum i.e., Levels 0,1 and 6 . These results also show that areas of concern exist for the maritime instructors and their utilization of information technologies in their teaching activities. Therefore, the MET institutions could provide more resources and/or training for the instructors for them to advance further on these levels of educational innovation, namely to Levels $4 \mathrm{~B}, 5$ and 6 . These levels correspond to the refinement, integration and renewal levels of use for technology in the classroom, respectively [40].

The findings indicate that the MET instructors feel sufficiently confident in the use of a majority of the technological affordances available to them; however, there is scope for improvement in their own pedagogical style and in utilizing collaborative knowledgecreating tools, as well as tools that enable the class to engage in a dynamic collaborative learning environment (e.g., social media/wiki/blogs). This facilitates online, distributed modes of learning in some instances of the course work, which is argued to support the acquisition of 21st century skills, such as collaboration and communication in the digital workspace [17]. It is also supported by the socio-constructivist perspective of teaching and learning, in which researchers suggest that knowledge is created in the learning context and then internalized by the student, with peers and technology often acting in mediation [44]. Many researchers have utilized Web 2.0 tools in postgraduate learning settings, with marked improvement in the student engagement in the classroom and innovation in their own practices $[45,46]$. Similarly, the use of more advanced and interactive technologies such as virtual and augmented reality learning tools deserves further scrutiny to estimate their viability in increasing student engagement and motivation for learning in the classroom context. 
The study also highlights the need to focus appropriate attention towards capacity building and technology integration in order for the MET instructors to improve the competitiveness of the MET institutes in general. Too often, and in a majority of cases rightly so, the discussions related to MET quality and value creation hover around the students and their profile, needs and learning style, etc. However, the MET instructors, who form a critical link in the value creation chain of the MET domain, remain under-researched [47]. In this regard, the discussions are often centered around infrastructure development for MET, and seldom on investment in terms of the continuous professional development of maritime instructors. The self-efficacy of maritime instructors towards the integration of technology and reflection towards their pedagogical approach also has implications for the competence development of maritime trainees. Even though the use of technological tools is acknowledged for active and interactive learning, for integrative learning with continuous assessment and for meaningful learning, the challenge for instructors to reflect on their attitudes towards technology is evident [48]. In order to translate their selfefficacy towards technology to meaningful pedagogical changes, [49] suggests that the constructivist orientation for teachers and proper guidance, as well as collaboration in using technological aids, could potentially increase the overall digital intervention in teaching. The increase in the qualifications of the instructors through structured training and capacity building can pay appropriate dividends to the MET institutes as they continue to focus on the pedagogical challenges of the current age with advancements in technology and the changing nature of maritime operations. A formal intervention by stakeholders in the maritime domain and regulatory bodies might be the need of the hour, in the form of changes in the regulations governing the qualifications of the MET instructors to cope with the need to transform maritime educational services and their delivery. Such a move influences the competence of the MET instructors and, by extension, the competence of the students, and also increases the innovation and value creation in the maritime domain. In summary, we would like to propose following recommendations for the stakeholders involved in Maritime Education and Training:

- Ensuring adequate support in the form of resources such as time allocation, and administrative and technical support to maritime instructors in order for them to be able to successfully advance their efforts to integrate technology into their practice.

- Changes in the regulatory frameworks and requirements that acknowledge the need for continuous professional development for maritime instructors specifically with the focus on digitalization and use of Web 2.0 tools.

- Reflection on the pedagogical practices that could provide learning frameworks which support the acquisition of 21st century skills.

The MET institutes should give special consideration in this regard, ensuring that adequate resources and a conducive environment are provided to the maritime instructors in order for them to achieve their goals and objectives for educational programs.

Some limitations of the present study also need to be outlined. Firstly, the sample size of the respondents could have been greater. This would have enabled the even greater generalizability of the results. A greater number of data points could also have enabled the use of inferential statistics (e.g., for regression) in contrast to the primarily descriptive statistics utilized in the study. Secondly, qualitative data in the form of open-ended questions could have been included in the questionnaire, allowing the MET instructors to communicate the reasons or barriers for the limited integration of technology tools in the classroom or their self-reported technological proficiency. Another apparent limitation is that the survey was answered predominantly by Western European nationalities. As such, the obtained data and the results are also a reflection of those geographical regions, and future studies-when conducted involving the rest of the European nationalitieswould provide better generalization, along with more data points. Finally, the utilization of questionnaire surveys in itself presents certain limitations. The use of a Likert scale in capturing the responses imposes a predetermined level of granularity on the responses, and deeper interpretation of the data is not possible due to the utilization of this design. 
Future studies related to technological integration in the classrooms of MET institutes should be related to the utilization of similar data collection measures in different geographical locations (e.g., in Asia), and should compare them with the European dataset. The more comprehensive modelling of the data utilizing structural equation modelling and regression analysis techniques is also possible if more data measures are included. These efforts could help in a more rigorous analysis of the self-reported technological proficiency of the MET instructors in the region, and the factors affecting it.

\section{Conclusions}

Maritime Education and Training plays an integral part in global maritime operations. The maritime instructors form a critical link in ensuring the competence development of maritime trainees. The capacity building of the MET instructors can play a vital role in the industry's transformation to deliver on future challenges. This study utilized a validated measure of self-reported technology proficiency, namely the Technology Proficiency Self-Assessment for the 21st Century (TPSA-C21), for the assessment of the technology self-efficacy scores of the MET instructors in the European states (and UK) along six dimensions. The results indicated a scope of improvement for the MET instructors in the better utilization of Web 2.0 tools, such as wiki, blogs and social media, i.e., teaching using a constructivist approach and emerging technologies. The results also highlighted the level of use of information technologies by the maritime instructors in their classrooms and the areas of improvement therein. The further adoption of additional measures into their teaching practices can mean the utilization of collaborative learning techniques in the classroom that bear the potential of better supporting remote and distributed modes of learning in the maritime classrooms. Maritime instructors with a higher level of technological self-efficacy could contribute to the training and education of a 21st century maritime work force that would require an additional and/or differential set of competences. The present study provides a suitable departure point for the further investigation of such topics. Future research should be directed toward gathering more samples from different nationalities, which would enable the greater generalization of the results, as well as comparing different geographical clusters in order to gain further insights for policy interventions.

Author Contributions: Conceptualization, A.S. and S.N.; methodology, A.S.; writing-original draft preparation, A.S.; writing-review and editing, A.S. and S.N.; visualization, A.S. and S.N.; supervision, S.N. Both authors have read and agreed to the published version of the manuscript.

Funding: This research was funded by the Department of Maritime Operations, University of South-Eastern Norway, PhD project no.2700077.

Institutional Review Board Statement: The study was conducted according to the guidelines of the Declaration of Helsinki, and the ethical permission to collect and process the data was obtained from the Norwegian Centre for Research Data (NSD) via a notification form, reference number 471618, on 18 March 2020.

Informed Consent Statement: Informed consent was obtained from all respondents involved in the study.

Acknowledgments: The authors would like to thank Charlott Sellberg and Gesa Praetorius for their guidance during the data collection stage.

Conflicts of Interest: The authors declare no conflict of interest.

\section{References}

1. IMO Secretary-General Launches 2015 World Maritime Day Theme: "Maritime Education and Training". Available online: http:/ / www.imo.org/en/MediaCentre/PressBriefings/Pages/02-WMD-launch.aspx\#.XqBPGMgzbZs (accessed on 22 April 2020).

2. Miller, M.B. Europe and the Maritime World: A Twentieth Century History; Cambridge University Press: Cambridge, UK, 2012.

3. Oksavik, A.; Hildre, H.P.; Pan, Y.; Jenkinson, I.; Kelly, B.; Paraskevadakis, D.; Pyne, R. Future Skills and Competence Needs; Skillsea Project: Rotterdam, The Netherlands, 2020. 
4. International Association of Maritime Universities (IAMU). Available online: https://iamu-edu.org/about-iamu/members / (accessed on 22 April 2020).

5. Burke, R.; Clott, C. Technology, collaboration, and the future of maritime education. In Proceedings of the Royal Institution of Naval Architects-International Conference on Education and Professional Development of Engineers in the Maritime Industry, Singapore, 20-21 September 2016.

6. Kadioglu, M. Information and Communication Technology (ICT) Training Application for MET Institutions. Int. J. Mar. Navig. Saf. Sea Transp. 2008, 2, 111-116.

7. Mallam, S.C.; Nazir, S.; Renganayagalu, S.K. Rethinking Maritime Education, Training, and Operations in the Digital Era: Applications for Emerging Immersive Technologies. J. Mar. Sci. Eng. 2019, 7, 428. [CrossRef]

8. Manuel, M.E. Vocational and academic approaches to maritime education and training (MET): Trends, challenges and opportunities. WMU J. Marit. Aff. 2017, 16, 473-483. [CrossRef]

9. Kitada, M.; Bolmsten, J.; Zeya, K.; Pham, T.H.; Aung, M.S. Learning theories meet virtual classroom technologies: Understanding new educational opportunities in maritime education and training. In Proceedings of the 18th Annual General Assembly of the IAMU, Varna, Bulgaria, 11-14 October 2017; pp. 72-81.

10. Boulougoris, E.; Mizythras, P.; Chrysinas, L.; Vavourakis, G.; Theotokatos, G.; Aymelek, M.; Kurt, I. Developing multidisciplinary blended learning courses for maritime education with cross-European collaboration. WMU J. Marit. Aff. 2019, 18, 319-340. [CrossRef]

11. Sharma, A.; Kim, T.-E. Exploring technical and non-technical competencies of navigators for autonomous shipping. Mar. Pol. Man. 2021. [CrossRef]

12. Bitner, N.; Bitner, J.O.E. Integrating technology into the classroom: Eight keys to success. J. Technol. Teach. Educ. 2002, 10, 95-100.

13. Davies, R.S.; West, R.E. Technology integration in schools. In Handbook of Research on Educational Communications and Technology; Bishop, M.J., Boling, E., Elen, J., Svihla, V., Eds.; Springer: New York, NY, USA, 2014; pp. 841-853.

14. Knezek, G.; Christensen, R. Extending the will, skill, tool model of technology integration: Adding pedagogy as a new model construct. J. Comput. High. Educ. 2016, 28, 307-325. [CrossRef]

15. Rogers, P.L. Barriers to adopting emerging technologies in education. J. Educ. Comput. Res. 2000, 22, 455-472. [CrossRef]

16. Vannatta, R.A.; Fordham, N. Teacher dispositions as predictors of classroom technology use. J. Res. Technol. Educ. 2004, 36, 253-271. [CrossRef]

17. Larson, L.C.; Miller, T.N. 21st century skills: Prepare students for the future. Kappa Delta Pi Rec. 2011, 47, 121-123. [CrossRef]

18. Saavedra, A.R.; Opfer, V.D. Learning 21st-century skills requires 21st-century teaching. Phi. Delta Kappan. 2012, 94, 8-13. [CrossRef]

19. De Água, P.M.G.B.; da Silva Frias, A.D.; Carrasqueira, M.D.J.; Daniel, J.M.M. Future of maritime education and training: Blending hard and soft skills. Pomorstvo 2020, 34, 345-353. [CrossRef]

20. Sellberg, C. Representing and enacting movement: The body as an instructional resource in a simulator-based environment. Educ. Inf. Technol. 2017, 22, 2311-2332. [CrossRef]

21. Kim, T.-E.; Sharma, A.; Bustgaard, M.; Gyldenstsen, W.; Nymoen, O.K.; Tusher, H.M.; Nazir, S. The continuum of simulator-based maritime training and education. WMU J. Marit. Aff. 2021, 20, 135-150. [CrossRef]

22. European Maritime Safety Agency (EMSA). Seafarer Statistics in EU-2018. Available online: http:/ / www.emsa.europa.eu/ publications/reports/item/3977-seafarer-statistics-in-the-eu-statistical-review-2018-data-stcw-is.html (accessed on 1 June 2021).

23. Ghosh, S.; Bowles, M. Management of berths at sea for seafarer students. Aust. J. Marit. Ocean. Aff. 2013, 5, 11-21. [CrossRef]

24. Muirhead, P.M. New technology and maritime training in the 21st century: Implications and solutions for MET institutions. WMU J. Marit. Aff. 2004, 3, 139-158. [CrossRef]

25. Guzman, A.; Nussbaum, M. Teaching competencies for technology integration in the classroom. J. Comput. Assist. Learn. 2009, 25, 453-469. [CrossRef]

26. Säljö, R. Digital tools and challenges to institutional traditions of learning: Technologies, social memory and the performative nature of learning. J. Comput. Assist. Learn. 2010, 26, 53-64. [CrossRef]

27. Johnson, T.; Wisniewski, M.A.; Kuhlemeyer, G.; Isaacs, G.; Krzykowski, J. Technology adoption in higher education: Overcoming anxiety through faculty bootcamp. J. Asynchronous Learn. Netw. 2012, 16, 63-72. [CrossRef]

28. Murdoch, D.; Fichter, R. From doing digital to being digital: Exploring workplace adoption of technology in the age of digital disruption. Int. J. Adult Vocat. Educ. Technol. IJAVET 2017, 8, 13-28. [CrossRef]

29. Brinkerhoff, J. Effects of a long-duration, professional development academy on technology skills, computer self-efficacy, and technology integration beliefs and practices. J. Res. Technol. Educ. 2006, 39, 22-43. [CrossRef]

30. Moore-Hayes, C. Technology integration preparedness and its influence on teacher-efficacy. Can. J. Learn. Technol. 2011, 37, 1-15. [CrossRef]

31. Bandura, A. Social Learning Theory; Prentice-Hall: Oxford, UK, 1977.

32. Bandura, A. Perceived self-efficacy in cognitive development and functioning. Educ. Psychol. 1993, 28, 117-148. [CrossRef]

33. Hoy, A.W.; Hoy, W.K.; Davis, H.A. Teachers' self-efficacy beliefs. In Handbook of Motivation at School; Wentzel, K., Wingfield, A., Eds.; Routledge: New York, NY, USA, 2009; pp. 627-654.

34. Christensen, R.; Knezek, G. Validating the technology proficiency self-assessment questionnaire for 21st century learning (TPSA C-21). J. Digit. Learn. Teach. Educ. 2017, 33, 20-31. [CrossRef] 
35. Christensen, R.; Knezek, G. The Technology Proficiency Self-Assessment Questionnaire (TPSA): Evolution of a Self-Efficacy Measure for Technology Integration. In KEYCIT 2014-Key Competencies in Informatics and ICT; Torsten, B., Reynolds, N., Romeike, R., Schwill, A., Eds.; University of Potsdam: Potsdam, Germany, 2014; pp. 311-318.

36. Ropp, M.M. Exploring individual characteristics associated with learning to use computers in preservice teacher preparation. J. Res. Comput. Educ. 1999, 31, 402-424. [CrossRef]

37. Miller, J.; Christensen, R.; Knezek, G. Effect of a Makerspace Training Series on Elementary and Middle School Educator Confidence Levels Toward Integrating Technology. In Proceedings of Society for Information Technology \& Teacher Education International Conference, Austin, TX, USA, 5 March 2017; Resta, P., Smith, S., Eds.; Association for the Advancement of Computing in Education (AACE): Austin, TX, USA, 2017; pp. 1015-1020.

38. Woods, K.D. Teacher Technology Efficacy: The Relationship among Generation, Gender, and Subject Area of Secondary Teachers. Ph.D. Thesis, Liberty University, Lynchburg, VA, USA, 2020.

39. Knezek, G.; Christensen, R.; Miyashita, K.; Ropp, M.M. Instruments for Assessing Educator Progress in Technology Integration; IITTL: Denton, TX, USA, 2000.

40. Griffin, D.; Christensen, R. Concerns Based Adoption Model Levels of Use of an Innovation (CBAM-LOU). Adapted from Hall, Loucks, Rutherford, \& Newlove (1975); Institute for the Integration of Technology into Teaching and Learning (IITTL): Denton, TX, USA, 1999.

41. Hall, G.E.; Loucks, S.F.; Rutherford, W.L.; Newlove, B.W. Levels of use of the innovation: A framework for analyzing innovation adoption. J. Teach. Educ. 1975, 26, 52-56. [CrossRef]

42. Hair, J.F.; Risher, J.J.; Sarstedt, M.; Ringle, C.M. When to use and how to report the results of PLS-SEM. Eur. Bus. Rev. 2019, 31, 2-24. [CrossRef]

43. Hair, J.F., Jr.; Howard, M.C.; Nitzl, C. Assessing measurement model quality in PLS-SEM using confirmatory composite analysis. J. Bus. Res. 2020, 109, 101-110. [CrossRef]

44. Vygotsky, L.S. Socio-cultural theory. In Mind in Society: Development of Higher Psychological Process; Cole, M., Jolm-Steiner, V., Scribner, S., Souberman, E., Eds.; Harvard University Press: Cambridge, MA, USA, 1978; pp. 52-58.

45. Su, F.; Beaumont, C. Evaluating the use of a wiki for collaborative learning. Innov. Educ. Teach. Int. 2010, 47, 417-431. [CrossRef]

46. Naismith, L.; Lee, B.H.; Pilkington, R.M. Collaborative learning with a wiki: Differences in perceived usefulness in two contexts of use. J. Comput. Assist. Learn. 2011, 27, 228-242. [CrossRef]

47. Vujičić, S.; Hasanspahić, N.; Gundić, A.; Hrdalo, N. Assessment for Ensuring Adequately Qualified Instructors in Maritime Education and Training Institutions. Athens J. Sci. 2020, 7, 115-124. [CrossRef]

48. Jääskelä, P.; Häkkinen, P.; Rasku-Puttonen, H. Teacher beliefs regarding learning, pedagogy, and the use of technology in higher education. J. Res. Technol. Educ. 2017, 49, 198-211. [CrossRef]

49. Gao, P.; Choy, D.; Wong, A.F.; Wu, J. Developing a better understanding of technology based pedagogy. Australas. J. Educ. Technol. 2009, 25. [CrossRef] 